\title{
The role of dentists in clinical tobacco cessation interventions: The status in Nigeria
}

\author{
Kehinde K. Kanmodi ${ }^{1,2}$
}

\section{AFFILIATION}

1 Tobacco Research and Advocacy Group, Cephas Health Research Initiative Inc, Ibadan, Nigeria

2 Department of Community Health, Aminu Musa Habib College of Health Science and Technology, Yauri, Nigeria

CORRESPONDENCE TO

Kehinde K. Kanmodi. Tobacco Research and Advocacy Group, Cephas
Health Research Initiative Inc, Ibadan, Nigeria. E-mail: kanmodikehinde@ yahoo.com

\section{KEYWORDS}

tobacco cessation, intervention, patient care, dentist, Nigeria

Received: 25 April 2020, Revised: 8 August 2020,

Accepted: 9 October 2020

Popul. Med. 2020;2(November):37

https://doi.org/10.18332/popmed/128323

\begin{abstract}
There are myriads of oral diseases associated with chronic tobacco use. Dentists are influential leaders in oral healthcare and many tobacco users do seek them for clinical care. However, in Nigeria, anecdotal and scientific evidence shows that dentists play little or no role in clinical tobacco cessation interventions. Many Nigeria dentists fail to play a role in clinical tobacco cessation interventions due to deficits in knowledge on clinical management of tobacco addiction. Unlike in some other foreign dental schools, clinical tobacco cessation intervention is not included in the
\end{abstract}

academic curriculum of dental schools in Nigeria. Hence, it is recommended that a review of the curriculum of dental education in Nigeria should be conducted, favoring the incorporation of tobacco cessation intervention into the curriculum. Also, clinical guidelines on the implementation of clinical tobacco cessation intervention strategies should be developed for Nigerian dentists.

ABBREVIATIONS CME: Continual medical education, LMICs: Low and middle income countries, NRT: Nicotine replacement therapy, NUC: Nigeria University Commission, MDCN: Medical and Dental Council of Nigeria

\section{COMMENTARY}

Tobacco is a leading cause of death globally, claiming the lives of 8 million people every year ${ }^{1}$. The burden of tobacco use is enormous with about 1.1 billion people in the world being smokers of tobacco and tobacco products ${ }^{1}$. The majority (at least $80 \%$ ) of these smokers are from LMICs, including Nigeria ${ }^{2}$.

There are myriads of oral diseases associated with chronic tobacco use $\mathrm{e}^{3,4}$ including gingivitis, periodontitis, periodontal abscess, oral pre-cancer, and oral cancer ${ }^{3,4}$.

A review of clinical cases of oral diseases managed in dental settings revealed that patients with a history of tobacco use had poorer health outcomes than patients that were non-users of tobacco ${ }^{5-7}$. A very effective way to stem the development of tobacco-associated oral diseases is through tobacco cessation interventions ${ }^{3}$.

Dentists are influential leaders in oral healthcare and many tobacco users do seek them for clinical care. Hence, through their clinical position, they can influence tobacco smokers toward quitting tobacco use ${ }^{5-8}$. However, in Nigeria, anecdotal and scientific evidence shows that dentists play little or no role in clinical tobacco cessation interventions 9

This brief research (case study) article has the aim of: giving an overview on the deficiency of dental education in Nigeria, as regards tobacco cessation, and the role of tobacco in the Nigerian oral healthcare system; giving a brief note on the role of dentists in clinical tobacco cessation intervention; and also giving policy recommendations that support the significant engagement of Nigerian dentists in clinical tobacco cessation interventions.

\section{Dental education in Nigeria}

Undergraduate training of dentists in Nigerian universities officially started at the University of Lagos, in $1964^{10}$. Thereafter, over the years, more and more dental schools have been established. According to the MDCN, there are 8 accredited dental schools in Nigeria ${ }^{11}$; this implies that Nigeria currently has the capacity to produce over 100 dentists per year. Since the commencement of undergraduate dental training in Nigeria, the academic curriculum of dental education has undergone a series of reviews and modifications ${ }^{12,13}$. Undergraduate dental education in Nigeria 
traditionally takes a minimum of six years and another one year of internship, after which a trained dentist in Nigeria can be fully registered with the $\mathrm{MDCN}^{13}$.

It is noteworthy to say that the academic curriculum of dental education in Nigeria is very rich and fortified ${ }^{13}$. However, the curriculum has some deficiencies ${ }^{9,13}$; for instance, the curriculum failed to include academic and clinical training on tobacco cessation intervention strategies, for dental students ${ }^{9}$. This curricular deficit is not a universal phenomenon, as some dental schools in other countries, such as Japan, have it included in their own academic curriculum ${ }^{8}$.

Furthermore, in the curriculum for postgraduate clinical training of dentists in Nigeria, there is no clear evidence that clinical training on tobacco cessation intervention strategies exists $^{9,14}$. However, based on the author's experience, the opportunities available for dental students or dentists who are willing to acquire extra-curricular clinical skills on tobacco cessation interventions are few and limited. A common example of these few opportunities is CME programmes, such as workshops, seminars, etc.

\section{Tobacco and dental practice}

As a practicing dentist in Nigeria, it is almost practically impossible not to have at least one tobacco user (usually a smoker) among the pool of patients treated at the dental clinic in a week. This is so because: 1 ) tobacco smoking is a common social practice in LMICs, like Nigeria'; and 2) tobacco is a leading cause of oral diseases ${ }^{4}$.

Since tobacco is a known major risk factor for so many oral diseases ${ }^{4}$, it becomes imperative for dentists to have a vast knowledge on tobacco-related clinical issues that are of relevance to dentistry. However, research has shown that not all Nigerian dentists have a sound knowledge on tobaccorelated clinical topics?.

Importantly, a dentist may be the first healthcare provider to detect early complications of tobacco use in a patient. Hence, it is of huge clinical and public health benefit if dentists can play decisive roles in tobacco cessation interventions, since scientific evidence has shown that clinical interventions offered by dentists, in a dental setting, increase the likelihood of a tobacco smoker to quit tobacco use $^{15}$.

\section{The situation of dentists' role in tobacco cessation intervention in Nigeria}

Raw tobacco is a nicotine-containing addictive psychoactive substance. Also, all products made from raw tobacco (such as snus, khaini, cigar, bidis, kreteks, cigarettes, shisha, and pipe) contain nicotine ${ }^{16,17}$.

Chronic consumption of tobacco and tobacco-products can cause nicotine addiction - tobacco nicotine dependence ${ }^{3,18}$. Fortunately, many tobacco users are willing to quit its use ${ }^{19}$.

There are two major strategic protocols developed to clinically manage tobacco nicotine dependency in patients $^{3,19,20}:$ 1) clinical counselling therapy; and 2) NRT.
The former involves non-pharmacological management of tobacco using patients while the latter involves the use of drugs in such management ${ }^{3,19,20}$.

Tobacco causes damage to the mouth ${ }^{4}$ - the primary jurisdiction of the dentist. Hence, a dental patient deserves to benefit from tobacco cessation intervention in order to have better oral health outcomes ${ }^{4-7}$. Based on the available evidence, dentists in Nigeria are playing very little or no role in supporting tobacco smoking dental patients to quit tobacco use. Research has shown that Nigerian dentists have inadequate knowledge on tobacco cessation strategies ${ }^{9,14}$.

\section{Ways forward}

The Nigerian dentist occupies a very influential position in patient care; in fact, they are one of the first-line healthcare practitioners sought for care, especially at the community level. Also, dentists can play an effective role in the creation of tobacco-free individuals, through their participation in counselling their patients to quit ${ }^{9,14,20}$.

\section{CONCLUSION}

It is recommended that a review of the curriculum of dental education should be done, with the primary focus of incorporating tobacco cessation intervention (such as clinical counselling therapy and NRT) as an integral part of the curriculum. A similar recommendation was also made by some Nigerian dentists" ${ }^{9}$ therefore, it is a serious issue for dental practice in Nigeria. Also, clinical guidelines for the implementation of clinical tobacco cessation intervention strategies should be developed for Nigerian dentists, as done in other countries ${ }^{21}$. Through the application of these two strategies, dentists trained in Nigeria will be in a better position to support tobacco-using dental patients to quit.

\section{REFERENCES}

1. World Health Organization. Tobacco. https://www.who.int/ news-room/fact-sheets/detail/tobacco. Published May 27, 2020. Accessed August 8, 2020.

2. World Health Organization, Regional Office for Africa. Tobacco control. https://www.afro.who.int/health-topics/ tobacco-control. Accessed August 8, 2020.

3. Odukoya O, Jamda M, Onigbogi O, et al. Tobacco Cessation Interventions in Tertiary Hospitals in Nigeria: An Audit of Patient Records. Nicotine Tob Res. 2017;19(8):983-989. doi:10.1093/ntr/ntw397

4. Rodu B, Godshall WT. Tobacco harm reduction: an alternative cessation strategy for inveterate smokers. Harm Reduct J. 2006;3:37. doi:10.1186/1477-7517-3-37

5. Reibel J. Tobacco and oral diseases. Update on the evidence, with recommendations. Med Princ Pract. 2003;12(Suppl 1):22-32. doi:10.1159/000069845

6. Baig MR, Rajan M. Effects of smoking on the outcome of implant treatment: a literature review. Indian J Dent Res. 2007;18(4):190-195. doi:10.4103/0970-9290.35831

7. Jiang X, Jiang X, Wang Y, Huang R. Correlation between 
tobacco smoking and dental caries: A systematic review and meta-analysis. Tob Induc Dis. 2019;17:1-8. doi:10.18332/tid/106117

8. Bao X, Liu F, Chen Q et al. Propensity score analysis exploring the impact of smoking and drinking on the prognosis of patients with oral cancer. Head Neck. 2020;42(8):18371847. doi:10.1002/hed.26099

9. Haresaku S, Hanioka T, Yamamoto M, Ojima M. Impact of a tobacco curriculum on smoking behaviour and attitudes toward smoking in dental students in Japan: a threeyear follow-up study. Int Dent J. 2011;60(2):99-105. PMID:20476715.

10. Dedeke AA, Popoola OA, Adebiyi AO, Asuzu MC. Tobacco cessation services and related challenges among dentists in southwest Nigeria. Ann Ib Postgrad Med. 2018;16(2):125130. PMID:31217769.

11. College of Medicine of the University of Lagos. Faculty of Dental Sciences, University of Lagos. About our faculty. College of Medicine of the University of Lagos. https://cmul. unilag.edu.ng/faculties/dental-sciences/. Accessed August 8, 2020.

12. Medical and Dental Council of Nigeria. Dental internship training centres accredited by Council. http://www. mdcnigeria.org/Dental\%20Schools.htm. Accessed August $8,2020$.

13. University of Ibadan. Prospectus 2006-2008: College of Medicine. Ibadan, Nigeria: University of Ibadan; 2006.

14. Isiekwe GI, Sofola 00, Sanu 00, Oredugba FA. Undergraduate dental curriculum of a Nigerian dental school and the behavioural science and management skills required for private dental practice. 2013;5(5):40-44. doi:10.5897/JDOH2013.0083

15. Nwafor NJ, Kanmodi KK, Omoleke SA, Enaibe TW. Knowledge of shisha and attitudes toward clinical counseling of shisha smokers amongst doctors: Nigerian study. Med J Zambia. 2020;47(1):16-24. https://mjz.co.zm/index.php/mjz/ article/view/637/419. Published January 1, 2020. Accessed August 8, 2020.

16. Omaña-Cepeda C, Jané-Salas E, Estrugo-Devesa A, ChimenosKüstner E, López-López J. Effectiveness of dentist's intervention in smoking cessation: A review. J Clin Exp Dent. 2016;8(1):e78-83. doi:10.4317/jced.52693

17. O'Connor RJ. Non-cigarette tobacco products: What have we learned and where are we headed?. Tob Control. 2012;21(2):181190. doi:10.1136/tobaccocontrol-2011-050281

18. Shaik FB, Maddu N. Smokeless tobacco products profile and pictorial warning labels in India: A review. Popul Med. 2019;1(December):1-6. doi:10.18332/popmed/114940

\section{CONFLICTS OF INTEREST}

The author has completed and submitted the ICMJE Form for Disclosure of Potential Conflicts of Interest and none was reported.

FUNDING

There was no source of funding for this research.
19. Widysanto A, Combest FE, Dhakal A, Saadabadi A. Nicotine Addiction. Treasure Island, FL: StatPearls Publishing; 2020. PMID:29763090.

20. Milcarz K, Makowiec-Dąbrowska T, Bak-Romaniszyn L, Kaleta D. Smoking Patterns and Smoking Cessation Willingness-A Study among Beneficiaries of Government Welfare Assistance in Poland. Int J Environ Res Public Health. 2017;14(2):131. doi:10.3390/ijerph14020131

21. Herman AI, Sofuoglu M. Comparison of available treatments for tobacco addiction. Curr Psychiatry Rep. 2010;12(5):433440. doi:10.1007/s11920-010-0134-6 